\title{
TECNOLOGIA E INOVAÇÃO ALIADAS À EDUCAÇÃO: O USO DE SOFTWARES EDUCACIONAIS PARA O ENSINO DE CIÊNCIAS E BIOLOGIA
}

\section{TECHNOLOGY AND INNOVATION ALLYED TO EDUCATION: THE USE OF EDUCATIONAL SOFTWARES FOR TEACHING SCIENCES AND BIOLOGY}

\author{
Ailton Donizetti dos Santos \\ Graduado em Ciências Biológicas, Universidade de Uberaba, Brasil. \\ E-mail: ailton.hevila@gmail.com \\ Derli Barbosa dos Santos \\ Mestre em ensino de Ciências, Professor do IFMG, Brasil. \\ E-mail: derli.santos@ifmg.edu.br
}

Recebido: 20/03/2021 - Aceito: 20/03/2021

\section{Resumo}

Este artigo discute a utilização de softwares educacionais aplicáveis ao ensino de Ciências e Biologia. O objetivo deste trabalho é identificar e apresentar softwares que possam ser utilizados no ensino de Ciências e Biologia. Justifica-se a elaboração do presente texto, na medida em que se ampliará as discussões sobre o tema, bem como constitui-se em uma forma de contribuir para a qualidade do ensino de Ciências e Biologia no Brasil, caracterizado nos últimos anos por ser um ensino pouco atrativo, de difícil aprendizagem e de baixa qualidade. A revisão bibliográfica foi o método utilizado para o desenvolvimento desta proposta. A constituição de uma lista de aplicativos e programas aplicáveis ao ensino de Ciências e Biologia foi o principal achado do estudo. Esperase que esta pesquisa possa contribuir com a implementação de aulas de Ciências e Biologia mais motivadoras e eficientes.

Palavras-chave: Tecnologias digitais; Processo ensino/aprendizagem; Escola.

\begin{abstract}
This article discusses the use of educational software applicable to the teaching of Science and Biology. The objective of this work is to identify and present software that can be used in the teaching of Science and Biology. The elaboration of this text is justified, as the discussions on the theme will be broadened, as well as constituting a way to contribute to the quality of science and biology teaching in Brazil, characterized in recent years by being a unattractive, difficult to learn and low quality teaching. The bibliographic review was the method used for the development of this proposal. The constitution of a list of applications and programs applicable to the teaching of Science and Biology was the main finding of the study. It is hoped that this research can contribute
\end{abstract}


to the implementation of more motivating and efficient Science and Biology classes.

Keywords: Digital technologies; Teaching / learning process; School.

\section{Introdução}

Os conhecimentos intrínsecos às ciências da natureza, nos quais estão incluídos aqueles de Ciências e Biologia, são muito abstratos e, por vezes, distantes do cotidiano dos estudantes (CAMAROTTI \& BEZERRA, 2010).

As aulas de Ciências e Biologia requerem a utilização de muitos experimentos, mecanismo que facilita a compreensão dos conteúdos, o que por sua vez demanda instrumentos e ambientes adequados para o desenvolvimento das aulas práticas, em geral, os laboratórios. Entretanto, a maioria das escolas públicas não conta com laboratórios de Ciências e aquelas que têm, quase sempre, estão em condições precárias de uso, por falta de fomento e manutenção.

O uso de softwares educacionais para o ensino de Ciências e Biologia pode funcionar como uma estratégia eficiente para o enfrentamento da falta e precariedade dos laboratórios de ciências das escolas públicas do Brasil, como também para minimizar o desinteresse dos alunos.

As tecnologias digitais são atualmente suportes que permeiam o mundo dos estudantes, pois a posse de smartphones é cada vez mais comum entre eles. Também tem se tornado cada vez mais crescente o desenvolvimento de softwares educacionais, entre estes, softwares direcionados ao ensino de Ciências e Biologia.

A partir da perspectiva apresentada, o objetivo deste trabalho é identificar e apresentar aplicativos e programas que sejam aplicáveis ao ensino de ciências e Biologia. Justifica-se a elaboração da presente pesquisa, na medida em que se ampliará as discussões sobre o tema, bem como constitui-se em uma forma de contribuir para a qualidade do ensino de Ciências e Biologia. Como resultado do levantamento realizado foi possível construir uma lista de softwares aplicáveis ao ensino de Ciências e Biologia. 


\title{
Revista Multidisciplinar do Nordeste Mineiro, v.1, 2021/01 \\ ISSN 2178-6925
}

Encontrar respostas na literatura especializada para o questionamento "os softwares educacionais podem otimizar as aulas de Ciências e Biologia?" foi o que norteou as buscas aqui realizadas.

Para a implementação deste trabalho, a pesquisa bibliográfica foi o método suporte do estudo. Conforme Martins e Theóphilo (2016, p. 52), a pesquisa bibliográfica,

\begin{abstract}
Trata-se de estratégia de pesquisa necessária para a condução de qualquer pesquisa científica. Uma pesquisa bibliográfica procura explicar e discutir um assunto, tema ou problema com base em referências publicadas em livros, periódicos, revistas, enciclopédias, dicionários, jornais, sites, CDs, anais de congressos etc. Busca conhecer, analisar e explicar contribuições sobre determinado assunto, tema ou problema. A pesquisa bibliográfica é um excelente meio de formação científica quando realizada independentemente - análise teórica - ou como parte indispensável de qualquer trabalho científico, visando à construção da plataforma teórica do estudo.
\end{abstract}

O levantamento bibliográfico foi constituído a partir de pesquisas realizadas no buscador "Google Acadêmico". "Softwares educacionais para ciências e biologia" foi a frase padrão utilizada nas pesquisas realizadas. Foram considerados para análise os trabalhos depositados na Biblioteca Digital de Ciências (BDC), bem como aqueles depositados em outras bibliotecas universitárias digitais e no "Scielo". O recorte de tempo considerado para a seleção das publicações foi o ano de 1990. Trabalhos publicados a partir deste ano e com os termos pesquisados foram analisados.

Para a elaboração de uma lista de softwares passíveis de seres utilizados no ensino de ciências e Biologia, considerou-se o seguinte: atualmente, é possível encontrar centenas de softwares para o fim aqui exposto, mas, que obviamente, não poderiam ser todos listados no espaço limitado de um artigo. Assim, foram priorizados na listagem final os softwares gratuitos e aqueles com abordagem dos conteúdos mais abstratos para os estudantes, como os relacionados à fisiologia vegetal e humana, genética, anatomia e citologia. Também foi utilizado o critério ciências, tecnologia, sociedade e ambiente (CTSA).

Este artigo foi estruturado em tópicos, os quais são iniciados com esta introdução, em que foi feita uma explanação geral do trabalho. A seguir apresentase a metodologia utilizada para o desenvolvimento da proposta. $O$ estabelecimento 
de reflexões sobre a história do ensino de Ciências e Biologia no Brasil é o assunto abordado no terceiro tópico. No quarto tópico tem-se uma abordagem do ensino de Ciências e Biologia no contexto das tecnologias digitais. A quinta parte, ocupa-se em fazer uma definição do conceito de softwares educacionais. Dentre as tecnologias digitais aplicáveis à aprendizagem, destaca-se no sexto tópico uma lista de softwares educacionais que podem ser utilizados na prática pedagógica de professores de Ciências e biologia. Por fim, são feitas algumas considerações gerais do trabalho, incluindo uma perspectiva do que se espera a partir da proposta aqui defendida.

\section{Revisão Bibliográfica}

\subsection{O Processo Ensino/Aprendizagem de Ciências e Biologia no Brasil: Breves Considerações}

Até o Renascimento, a Ciência estava diretamente vinculada ao campo do pensamento filosófico. A partir do Renascimento, a Ciência vai se constituindo como um meio pelo qual é possível explicar concretamente os fenômenos naturais. Nesse cenário, o mito acaba perdendo sua hegemonia enquanto recurso utilizado para explicar os fenômenos naturais. Também é extremamente abalada a influência da igreja enquanto tradutora divina da natureza.

[...] mesmo sob a influência da Igreja, as divergências relativas aos estudos dos fenômenos naturais prenunciaram mudanças de pensamento em relação às concepções, até então hegemônicas, sobre aqueles fenômenos (PARANÁ, 2008, p. 39).

Esse não foi o nascimento propriamente dito das Ciências enquanto disciplina acadêmica, mas foi o momento em que se consolidou o paradigma que sustentou o novo modelo de Ciências, que mais tarde chegaria às escolas.

A constituição da escola é um processo determinado por fatores políticos e sociais. Assim, a história do ensino de Ciências e Biologia no Brasil foi escrita paralelamente ao desenvolvimento político e social do Brasil (KRASILCHIK apud MORAES \& BATISTA, 2000). 
No contexto do Brasil colônia, o foco educacional centrava-se no processo de catequização e na aprendizagem de leitura, escrita e dos cálculos fundamentais. Nessa época, a educação era de responsabilidade dos jesuítas.

No início do século XIX, as ciências não eram ensinadas nas escolas brasileiras, mas, já era um conhecimento notável, muitas vezes temas de palestras ministradas para alguns membros da corte, até mesmo para Dom Pedro II (LOREZ apud MORAES \& BATISTA, 2008).

Contudo, o ensino de Ciências tornou-se parte do currículo das escolas brasileiras, somente no século XX. A Lei de Diretrizes e Bases da Educação, de 1961, Lei oㅜ 4024, determinava aulas de Ciências para os dois últimos anos da etapa da educação básica que atualmente é conhecida como $8^{\circ}$ ano e $9^{\circ}$ ano do Ensino Fundamental.

Nesse cenário, eram predominantes as aulas expositivas baseadas em livros didáticos escritos por cientistas e não por professores. Dessa forma, os professores apenas tinham a função de transmitir conteúdos totalmente distante da vida dos estudantes e até mesmo de suas próprias vidas.

Delizoicov e Angotti (1990, p. 27) afirmam que as ciências:

(...) atingiram os cursos de formação, consequentemente os professores e, sobretudo, a produção de livros-texto comerciais. Estes sim atingiram as salas de aula e se constituem cada vez mais no instrumento básico de trabalho dos professores, sempre impregnados com traços daquelas tendências.

Após a Ditadura Militar instalada em 1964, a educação escolar passou a ter como objetivo a formação técnica para o trabalho. Nesse ínterim, dava-se a formação técnica a nível médio e a especializada a nível superior.

Com a reforma universitária, de 1968, e a instituição do vestibular como forma de acesso ao Ensino Superior, este passou a ter grande força normativa em relação ao conteúdo, e mesmo à forma, do ensino das matérias científicas nos níveis anteriores. A concorrência classificatória induz observância estrita aos conteúdos programáticos restritos a conteúdos conceituais editados pelos próprios órgãos responsáveis pelos exames vestibulares. [...] Em grande parte, essa concorrência levou ao surgimento dos chamados cursinhos, que acabaram por cristalizar modelos de formação para o Ensino Médio, ligados a conteúdos programáticos muito extensos, baseados na memorização, e que exigem pouca vivência do método científico e quase nenhum trabalho cooperativo (BIZZO, 2004, p.153). 


\section{Revista Multidisciplinar do Nordeste Mineiro, v.1, $2021 / 01$ \\ ISSN 2178-6925}

Com a promulgação da Lei no 5626 de 1971, o ensino de Ciências tornouse obrigatório para o ensino Fundamental e Médio. Nesse contexto, o mundo experimentava a implementação da democracia em todos os setores da vida em sociedade e foi na década de 1970 que os ideais democráticos começaram a ganhar força no solo brasileiro. Nessa perspectiva, concepções cognitivistas passaram a ter muita ênfase no cenário educacional. Nessa nova realidade educativa, passou-se a preconizar o ensino do método científico para se ensinar e aprender Ciências. O objetivo maior era a formação de cientistas. Todavia, o método científico não pode ser reduzido aos experimentos de uma aula de Ciências, o que fez com que essa abordagem passasse a ser questionada.

Atrelada às discussões sobre os problemas ambientais e a necessidade do desenvolvimento sustentável, surge na década de 80, o movimento Ciências, Tecnologia, Sociedade e Ambiente (CTSA), o qual no que concerne ao ensino/aprendizagem de Ciências e Biologia visa:

\footnotetext{
Melhorar a qualidade do ensino de Ciências nos diferentes níveis de ensino nas áreas de química, física, biologia e matemática; estimular, na universidade, a pesquisa científica na área do ensino de Ciências com a finalidade de gerar uma melhoria qualitativa do mesmo, especialmente em nível do ensino fundamental e médio; desenvolver atividades não formais de ensino, de modo a provocar uma valorização da ciência pela sociedade e despertar nos jovens um maior interesse pelo estudo de Ciências (FRACALANZA, 2009, p.37-38).
}

Portanto, a concepção de hegemonia científica e o conteúdismo que permeiam o ensino de Ciências e Biologia, atualmente, precisam dar lugar ao processo de formação em que o conhecimento científico deve ser o ponto de partida para a resolução de problemas e intervenção crítica e autônoma na sociedade.

Dito de outra forma, a ciência deve fomentar a tecnologia e ambas devem possibilitar a relação harmônica entre os seres vivos e não vivos, de modo que haja um constante equilíbrio entre a sociedade e o ambiente.

\subsection{A Prática Pedagógica De Ciências E Biologia No Contexto Das Tecnologias Digitais}




\section{Revista Multidisciplinar do Nordeste Mineiro, v.1, $2021 / 01$ \\ ISSN 2178-6925}

No cenário de constantes mudanças, como é o atual, falar em presente e passado é por vezes arriscado, tendo em vista que na era da evolução, a linha entre estes dois tempos tem sido cada vez mais tênue.

Há um entendimento de que vivemos uma nova sociedade. Uma sociedade que, em um período muito breve de tempo, tem passado por mudanças significativas nos mais diversos âmbitos, social, político e econômico identificando a presença cada vez mais acentuada de tecnologias da informação e da comunicação (CARLI, 2013, p.21).

Dessa forma, o futuro tem se tornado um tempo cada vez mais próximo. No entanto, a dinâmica escolar tem se mantido sempre em desvantagem com relação a essas mudanças bruscas nos modos de ser e fazer das sociedades contemporâneas.

A era tecnológica trouxe um grande impacto para o fazer pedagógico, pois os alunos não só se interagem com as novas tecnologias, como também são frutos da era tecnológica. Assim, os docentes precisam mover-se no sentido de estabelecer maneiras para se atualizarem e terem condições de mediarem aulas contextualizadas.

Toda e qualquer profissão hoje, exige de seus profissionais que estejam sempre buscando o aperfeiçoamento, isso por que, o mundo está continuamente em processo de evolução e as pessoas cada vez mais conectadas umas com as outras (MOURA E BRANDÃO, 2013, p.1).

Nessa perspectiva, na contemporaneidade tem surgido novos métodos de intervenção com vistas à auxiliar os professores na tarefa de construírem práticas pedagógicas inovadoras.

As tecnologias digitais surgem como instrumentos pedagógicos aliados à inovação na Educação. Nesse sentido, defende-se o uso de tecnologias digitais nos processos educativos, pois acredita-se que os mesmos podem tornar as aulas mais significativas. As tecnologias alteram a metodologia das aulas, essas mudanças devem partir da gestão escolar com o objetivo de usufruir dessas tecnologias para que 0 ensino se torne mais produtivo (MORAIS, 2003).

Em muitas salas de aula persiste a resistência de docentes no que se refere à utilização das tecnologias digitais. Ora sob o argumento de não domínio das mesmas, outras vezes, apoiados pelo fato de as escolas não contarem com 


\section{Revista Multidisciplinar do Nordeste Mineiro, v.1, 2021/01 \\ ISSN 2178-6925}

tais recursos. Não obstante, a contribuição destas ferramentas não pode continuar sendo ignorada, visto que,

O que se vem afirmando na literatura e na experiência até aqui construída é que no cenário escolar integrado com vivências em multimídia, estas geram: a dinamização e ampliação das habilidades cognitivas, devido à riqueza de objetos e sujeitos com os quais permitem interagir; a possibilidade de extensão da memória e de atuação em rede; ocorre a democratização de espaços e ferramentas, pois estas facilitam o compartilhamento de saberes, a vivência colaborativa, a autoria, coautoria, edição e a publicação de informações, mensagens, obras e produções culturais tanto de docentes como de discentes. (SOUZA, 2011, p. 22).

Portanto, o uso de softwares educacionais no ensino de Ciências e Biologia é uma forma de se resolver dois entraves educacionais das escolas públicas brasileiras: a promoção de aulas inovadoras e contextualizadas e a carência de laboratórios de Ciências.

Mello (2012, p. 446), aponta outra vantagem da utilização de softwares nas salas de aula:

O universo de conteúdos à disposição das editoras ampliou-se enormemente. A limitação existente para o conteúdo impresso em livros que pode contar com textos, imagens, fotografias, gráficos etc., mas não pode, por exemplo, englobar vídeos e sons - fica superada com a produção de todos esses conteúdos em formato digital.

Diante disso, afirma-se que o uso de softwares educacionais é a resposta pedagógica para o velho questionamento: como otimizar o ensino de Ciências e Biologia mediante à carência de recursos didáticos/pedagógicos nas escolas públicas?

\subsection{Softwares Educacionais}

O software educacional é aquele que possibilita ao docente o exercício eficiente de sua prática pedagógica. Assim, trata-se de dispositivos que através de recursos diversos, como imagens, textos, animações e outros, fazem abordagem aos conteúdos curriculares. Nesse sentido, o software educacional pode ser 


\title{
Revista Multidisciplinar do Nordeste Mineiro, v.1, $2021 / 01$ \\ ISSN 2178-6925
}

produzido exclusivamente para fins educativos, ou pode se tratar de uma ferramenta aplicável à educação.

Um exemplo de software que funciona como uma ferramenta aplicável à educação são os editores de texto e as tabelas e planilhas, os quais os professores podem lançar mão para a mediação de conteúdos, mas, que não foram criados especificamente para esse fim.

Conforme Lucena (1993, p. 02),

\begin{abstract}
Software é um programa que, associado ao sistema de computação, torna a máquina funcional e sua utilização eficiente. Para o estudo de uma estratégia para a introdução dos computadores na escola há a necessidade de se associar o computador ao chamado "software educacional". Os softwares educativos auxiliam a interação entre o aluno e o professor dentro do ambiente de aprendizagem, por isso existe a importância em avaliar softwares educativos que encontramos no mercado e a sua qualidade.
\end{abstract}

Além dos softwares classificados como ferramenta, há também o software tutelado e o software tutor. O software tutelado é aquele que o usuário fornece comandos para que o computador possa executar uma ação. Nesta categoria, citase a linguagem de programação "Logo", na qual o usuário fornece comandos a serem executados por uma tartaruga e pode obter diversas figuras geométricas. Cabe ressaltar que existe uma variedade de softwares educacionais neste formato.

No caso do software tutor, é o software que fornece comandos a serem executados pelo usuário. Nesta categoria, estão os jogos, as atividades de exercício e prática e os simuladores.

Existe uma grande variedade de softwares educacionais disponíveis. Estes softwares podem enriquecer e tornar mais eficiente e prazerosa as aulas de um professor. Existem softwares, como os simuladores, capazes de testar diferentes alternativas para a resolução de um problema. Podem também viabilizar o raciocínio lógico e levar os alunos a fazerem inferências, ao tirarem diferentes conclusões de cada resultado alcançado (BONA, 2009).

A utilização de softwares educacionais tem sido cada vez mais frequente. Por isso, diversos especialistas têm se debruçado no estudo exaustivo do tema. 
José Armando Valente é um desses especialistas, o qual considera a utilização do software educativo como extremamente benéfica:

\footnotetext{
"Quando o aluno usa o computador para construir o seu conhecimento, o computador passa a ser uma máquina para ser ensinada propiciando condições para o aluno descrever a resolução de problemas, usando linguagens de programação, refletir sobre resultados e depurar suas ideias" (VALENTE 1993, p. 12).
}

Contudo, ressalta-se a importância do professor ser capacitado para a utilização eficiente dos softwares educacionais, pois é este que vai avaliar a qualidade do conteúdo abordado, a coerência com sua abordagem e o tipo de mediação exigida.

O software educacional não é um professor substituto, é apenas um recurso didático/pedagógico contextualizado e dinâmico.

O uso da Informática na escola precisa de quatro ingredientes básicos: 0 software educativo, o computador, o professor capacitado para usar o computador como ferramenta educacional e o aluno (VALENTE, 1993).

Atualmente, existem diversos softwares educacionais para o ensino de Ciências e Biologia, muitos deles gratuitos. Assim, no tópico a seguir, foi construída uma lista com diversos softwares aplicáveis ao ensino de Ciências e Biologia.

\subsection{Softwares Educacionais Aplicáveis Ao Processo Ensino/Aprendizagem De Ciências E Biologia}

Acredita-se que os softwares educacionais para o ensino de Ciências e Biologia constituem-se em instrumentos pedagógicos inovadores e contextualizados. A partir dessa premissa, é que se construiu uma lista com a indicação de alguns softwares educacionais capazes de otimizar as aulas de Ciências e Biologia.

Os softwares selecionados na pesquisa encontram-se organizados na tabela a seguir, na qual foi discriminado o nome do software, seu conteúdo e a compatibilidade com sistemas operacionais. 


\section{Quadro 1 - Softwares educacionais para o ensino de Ciências e Biologia}

\begin{tabular}{|c|c|c|}
\hline $\begin{array}{c}\text { Software } \\
\text { educacional }\end{array}$ & Conteúdo & $\begin{array}{l}\text { Compatibilidade com } \\
\text { sistema operacional }\end{array}$ \\
\hline $\begin{array}{l}\text { Fisiologia das } \\
\text { plantas }\end{array}$ & $\begin{array}{l}\text { O aplicativo "Fisiologia das plantas" é um } \\
\text { aplicativo para celular que aborda temas } \\
\text { do conteúdo de fisiologia vegetal do ensino } \\
\text { médio. Dentre os temas abordados, cita-se } \\
\text { a morfologia das plantas e tipos, além de } \\
\text { outras características. }\end{array}$ & Android \\
\hline Fisiologia humana & $\begin{array}{l}\text { Para enriquecer as aulas de fisiologia } \\
\text { humana, os professores têm a opção de } \\
\text { usar em suas aulas o aplicativo "Fisiologia } \\
\text { humana", onde os temas do conteúdo são } \\
\text { expostos de forma breve e clara. Também } \\
\text { é possível participar de um quiz } \\
\text { relacionado com a abordagem. }\end{array}$ & Android \\
\hline Heredty & $\begin{array}{l}\text { O estudo de genética, geralmente avaliado } \\
\text { como muito abstrato, pode ser mediado } \\
\text { com o apoio do aplicativo "Heredty", que } \\
\text { aborda temas como a hereditariedade, } \\
\text { mitose, meiose e cromossomos, dentre } \\
\text { outros. }\end{array}$ & Android \\
\hline $\begin{array}{l}\text { Sistemas funcionais } \\
3 \mathrm{D}\end{array}$ & $\begin{array}{l}\text { As aulas de anatomia podem ficar mais } \\
\text { dinâmicas com o uso do aplicativo } \\
\text { "Sistemas do corpo humano 3D". Neste } \\
\text { aplicativo, os estudantes podem acessar } \\
\text { características detalhadas dos órgãos do } \\
\text { corpo humano, bem como um } \\
\text { mapeamento do sistema circulatório e } \\
\text { digestório com a disponibilização de } \\
\text { modelos tridimensionais dos órgãos. }\end{array}$ & Android \\
\hline
\end{tabular}




\begin{tabular}{|c|c|c|}
\hline Células & $\begin{array}{l}\text { No aplicativo "Células", alunos e } \\
\text { professores podem desvendar com } \\
\text { detalhes toda a estrutura da unidade } \\
\text { básica da vida, além dos diversos } \\
\text { mecanismos celulares. Tudo isso através } \\
\text { de modelos tridimensionais. }\end{array}$ & Android \\
\hline $\begin{array}{c}\text { Esqueleto/Anatomia } \\
\text { 3D }\end{array}$ & $\begin{array}{l}\text { O esqueleto, figura tão satirizada das } \\
\text { aulas de Ciências, pode ser explorado } \\
\text { virtualmente pelo aplicativo } \\
\text { "Esqueleto/anatomia 3D", no qual é } \\
\text { possível visualizar e manipular os ossos e } \\
\text { órgãos do esqueleto humano. }\end{array}$ & Android \\
\hline Desafio ambiental & $\begin{array}{l}\text { O "Desafio ambiental” é um aplicativo onde } \\
\text { o usuário é desafiado a fazer mudanças no } \\
\text { planeta. O usuário é incentivado com } \\
\text { pontuações e mudança de níveis. No } \\
\text { aplicativo, também são disponibilizadas } \\
\text { notícias sobre a qualidade do ar no país e } \\
\text { em sua cidade, além de informações de } \\
\text { poluição, ecossistema e outros dados } \\
\text { ambientais sobre o seu país. }\end{array}$ & Android \\
\hline $\begin{array}{l}\text { Curso de } \\
\text { astronomia }\end{array}$ & $\begin{array}{l}\text { O "Curso de astronomia" trata-se de um } \\
\text { aplicativo com noções básicas de } \\
\text { astronomia. O estudo dos planetas, } \\
\text { asteroides, estrelas e outros corpos } \\
\text { celestes vai ficar mais interativo com esse } \\
\text { aplicativo. }\end{array}$ & Android \\
\hline Microscopia & $\begin{array}{l}\text { O "Microscopia" disponibiliza acesso a } \\
\text { várias imagens microscópicas, geradas } \\
\text { por microscópios de última geração, pois } \\
\text { trata-se de um projeto da Nasa. }\end{array}$ & $\begin{array}{c}\text { Windows, Linux e } \\
\text { MacOs }\end{array}$ \\
\hline
\end{tabular}


Revista Multidisciplinar do Nordeste Mineiro, v.1,

$2021 / 01$

ISSN 2178-6925

\begin{tabular}{|c|c|c|}
\hline Giárdia & $\begin{array}{l}\text { O software "Giárdia" é um programa que } \\
\text { apresenta o ciclo de vida da Giardia sp, os } \\
\text { métodos profiláticos de prevenção da } \\
\text { giardíase e os sintomas e meios de } \\
\text { transmissão. Toda essa abordagem é feita } \\
\text { por meio de animação divertida. }\end{array}$ & $\begin{array}{l}\text { Compatível com } \\
\text { todos os sistemas } \\
\text { operacionais. }\end{array}$ \\
\hline Meiosis & $\begin{array}{l}\text { O "Meiosis" é um aplicativo de animações, } \\
\text { no qual informações e imagens sobre o } \\
\text { processo da meiose são demonstradas } \\
\text { com muita eficiência. }\end{array}$ & Android \\
\hline Vitual Cell & $\begin{array}{l}\text { Neste aplicativo é possível desvendar o } \\
\text { mundo das células com muita precisão. }\end{array}$ & Android \\
\hline Cell defender & $\begin{array}{l}\text { Aplicativo que apresenta as cinco } \\
\text { principais estruturas celulares e ainda } \\
\text { mostra os mecanismos de defesa das } \\
\text { células. }\end{array}$ & Android \\
\hline Bioninja & $\begin{array}{l}\text { Aplicativo para iniciantes onde o estudante } \\
\text { tem acesso a vários testes que abordam } \\
\text { todo o currículo de ciências. }\end{array}$ & Android \\
\hline Recycle games & $\begin{array}{l}\text { Com esse aplicativo é possível interagir } \\
\text { com todo o processo da reciclagem a partir } \\
\text { de um game bem animado. }\end{array}$ & iOs \\
\hline $\begin{array}{c}\text { S. O. S Mata } \\
\text { Atlântica: o jogo }\end{array}$ & $\begin{array}{l}\text { Para conhecer melhor a riqueza e a } \\
\text { biodiversidade da Mata Atlântica através } \\
\text { do aplicativo. }\end{array}$ & iOs \\
\hline Gene Screen & $\begin{array}{l}\text { Tenha acesso a um super mapa genético, } \\
\text { a calculadoras genéticas e faça um } \\
\text { rastreio genético. Neste aplicativo é } \\
\text { possível desvendar em detalhes os } \\
\text { mistérios da genética. }\end{array}$ & Android \\
\hline
\end{tabular}




\begin{tabular}{|l|l|l|}
\hline Bioquiz & $\begin{array}{l}\text { Este é um aplicativo ideal para fixar os } \\
\text { conteúdos trabalhados através da } \\
\text { proposição de quiz de Ciências. }\end{array}$ & Android \\
\hline O corpo & $\begin{array}{l}\text { Para explorar melhor com estudantes } \\
\text { iniciantes o maravilhoso corpo humano. }\end{array}$ & iOS \\
\hline
\end{tabular}

Fonte: Elaborado pelo autor

A disponibilidade de softwares e aplicativos de Ciências e Biologia é imensa. A pretensão aqui foi listar uma quantidade ínfima, de modo a instigar cada professor a lançar-se no desafio didático de pesquisar softwares e aplicativos compatíveis com suas aulas. Essa não vai ser uma tarefa difícil, pois o cenário das tecnologias educacionais digitais é cada vez mais crescente.

\section{Considerações Finais}

Em suma, concluiu-se com o estudo, que os softwares educacionais para o ensino de Ciências e Biologia são capazes de otimizar as aulas destas disciplinas. Dessa forma, encontrou-se com a realização da presente pesquisa, uma resposta positiva para a indagação inicial do trabalho.

Os softwares educacionais para o ensino de Ciências e Biologia podem otimizar as aulas porque são atraentes, motivadores e dinâmicos. Assim, são capazes de seduzir e envolver os estudantes. O uso destes recursos auxilia o professor a aproximar a escola da sociedade. Uma tarefa que tem sido desafiante para a todos os envolvidos com a educação.

Contudo, ficou evidente que a eficácia da utilização dos softwares educacionais nas aulas de Ciências e Biologia está condicionada a alguns fatores que de forma alguma, podem ser desconsiderados. O uso destes softwares deve ser resultado de um planejamento coerente do professor e de uma mediação direcionada e consciente. Não basta apenas disponibilizar nas aulas os softwares para que os estudantes explorem arbitrariamente. Antes, é preciso selecionar o melhor software considerando os objetivos da aula, a consonância com o currículo e a disponibilidade dos recursos de base, como sistema operacional, internet e outros. 
Revista Multidisciplinar do Nordeste Mineiro, v.1,

2021/01

ISSN 2178-6925

Nesse sentido, espera-se que a lista de softwares educacionais aplicáveis ao ensino de Ciências e Biologia e as discussões desenvolvidas neste artigo possam fomentar aulas de Ciências e Biologia mais dinâmicas e com mais qualidade. Além disso, que este seja um meio que viabilize a inserção docente no universo didático/pedagógico da informática.

\section{Referências}

BIZZO, N. Ciências biológicas: orientações curriculares para o ensino médio. Brasília: MEC/SEB, 2004. p.148-169.

BONA, Berenice de Oliveira. Análise de Softwares educativos para o ensino de Matemática nos anos iniciais do Ensino Fundamental. Universidade Luterana do Brasil. Carazinho, RS - Brasil. Disponível em:

<www.if.ufrgs.br/eenci/artigos/Artigo ID71/v4 n1 a2009.pdf> Acesso em 05 de fev. 2021.

CAMAROTTI, Maria de Fátima; BEZERRA, Areta Vieira. Softwares educacionais e o seu uso no ensino de Biologia. Universidade Federal da Paraíba, 2010.

Disponível em: <http://www.ccen.ufpb.br/cccb/contents/monografias/2010.1/arethavieira-bezerra.pdf.> Acesso em 30 de dez. 2020.

CARLI, A. Efeitos da introdução das TIC's no ensino de Ciências na Educação Básica.2013. 72.f. (Dissertação de Mestrado em Ciências: Química da Saúde e da Vida) UFRGS, Porto Alegre.

DELIZOICOV, D. e ANGOTTI, J. A. P. Metodologia do ensino de ciências. São Paulo: Cortez, 1990. (Coleção magistério $2^{\circ}$ grau. Série formação do professor).

FRACALANZA, H. Histórias do ensino de biologia no Brasil. In: SELLES, S. E. et. al. (Orgs). Ensino de biologia: histórias, saberes e práticas formativas.

Uberlândia: EDUFU, 2009. p. 25-48. 
GOUVEIA, M. S. F. Cursos de Ciências para professores do $1^{\circ} \mathrm{grau}$ : elementos para uma política de formação continuada. Tese (Doutorado em Educação).

Faculdade de Educação. Unicamp, Campinas, São Paulo, 1992, 283p.

\section{LUCENA, M.W.F.P. O Uso das Tecnologias da Informática para o}

Desenvolvimento da Educação. Rio de Janeiro 1994.

MARTINS, G. de A.; THEÓPHILO, C. R. Metodologia da investigação científica para ciências sociais aplicadas. ํㅜ․ ed. São Paulo: Atlas, 2016.

MELLO, G. Desafios para o setor editorial brasileiro de livros na era digital. BNDES Setorial 36, p. 446. 2012. Disponível em:

<https://web.bndes.gov.br/bib/jspui/bitstream/1408/1486/1/A\%20set.36_Desafios\% 20para\%200\%20setor\%20editorial\%20brasileiro\%20de\%20livros\%20na\%20era\%2 Odigital_P.pdf>Acesso: 15 de jan. 2021.

MORAIS, R.X.T. Software educacional: A importância de sua avaliação e de seu uso na sala de aula. Fortaleza: FLF, 2003. Disponível em:

$<$ <ttp://www.flf.edu.br/revista-flf/monografias-computacao/monografia-rommelxenfonte.pdf.> Acesso em 01 de fev. 2021.

MORAIS, Renan Rangel; BATISTA, Inara Carolina da Silva. História do ensino de Ciências na Educação Básica no Brasil (do Império até os dias atuais).

Disponível em: <https://educacaopublica.cecieri.edu.br/artigos/19/26/historia-doensino-de-ciencias-na-educacao-basica-no-brasil-do-imperio-ate-os-dias-atuais> Acesso em 23 de jan. 2021.

MOURA. E; BRANDÃO. E. O uso das tecnologias digitais na modificação da prática educativa escolar. Revista Fazer. Erechim, v. 1, №1.

PARANÁ. SECRETARIA DE ESTADO DA EDUCAÇÃO DO PARANÁ. Diretrizes Curriculares da Educação Básica: Biologia. Curitiba: Imprensa Oficial, 2008. 
Revista Multidisciplinar do Nordeste Mineiro, v.1,

SOUZA, R. P.; MOITA, F. da M. C. da S. C., CARVALHO, A. B. G. C. Tecnologias digitais na educação. Campina Grande: EDUEPB, 2011.

VALENTE, José Armando. Diferentes usos do computador na educação. NIED UNICAMP 1993. Disponível em:

$<$ http://www.proinfo.mec.gov.br/upload/biblioteca/187.pdf $>$ Acesso em: 30 de jan. 2021.

VALENTE, Jose Armando. O computador na sociedade do conhecimento.

Campinas, SP: UNICAMP/NIED, 1999. Disponível em: <

$\mathrm{br} /$ catedraunescoead/areas/menu/publicacoes/livros-de-interesse-na-area-de-ticsnaeducacao/o-computador-na-sociedade-do-conhecimento>Acesso em 20 de jan. 2021. 